\title{
EFFECT OF DIFFERENT FINAL IRRIGATION ACTIVATION METHODS ON ROOT CANAL CLEANLINESS
}

\author{
Randa Ahmed Elsobky* ${ }^{*}$,Abeer Mostafa Darrag ${ }^{* * *}$ and Neveen Ali Shaheen ${ }^{* * *}$
}

\begin{abstract}
Aim: to evaluate canal cleanliness after using manual dynamic activation, passive ultrasonic irrigation and photoactivated disinfection in comparison with conventional needle irrigation, using scanning electron microscopy
\end{abstract}

Methods: Sixty single rooted human premolars with nearly straight single canal were collected, the crowns of all teeth were removed near the level of cementoenamel junction to obtain approximately $15 \pm 1 \mathrm{~mm}$ uniform root lengths. After instrumentaion with ProTaper Next files up to X4 (40/06), roots were randomly divided into 4 equal groups $(n=15)$ according to the method of final irrigation activation. Group I: Conventional needle and syringe irrigation. Group II: Manual dynamic activation. Group III: passive ultrasonic irrigation. Group IV: photoactivated disinfection. Canal cleanliness was evaluated with SEM using different magnification (X350- X1000).

Results: Group III had the best cleanliness of the root canal while Group I had the worst cleanliness, there were statistical significant differences between Group I versus Groups II and III and between Group III and Group IV $(P \leq 0.05)$. Regardless the irrigation activation method, the coronal level showed significantly less amount of smear layer and remaining debris than the apical level.

Conclusions: None of the tested final irrigation activation methods resulted in completely clean canal wall.

KEYWORDS: Canal cleanliness, manual dynamic activation, passive ultrasonic irrigation, photoactivated disinfection, scanning electron microscopy.

\section{INTRODUCTION}

Whenever dentine is cut using either hand or rotary instruments, the mineralized tissues are shattered producing quantities of debris that is made of small particles of mineralized collagen matrix, forming what is called the smear layer. The smear layer consists of organic and inorganic materials, including parts of odontoblastic processes, microorganisms and necrotic tissues ${ }^{[1]}$.

\section{* B.D.S (2011)}

** Professor of Endodontics, Faculty of Dentistry, Tanta University

*** Assistant Professor of Endodontics, Faculty of Dentistry, Tanta University 
Irrigation is a key part of the root canal treatment. It is the best method for smear layer removal by flushing away loose, necrotic, and contaminated materials before they invade deeper into the canal. Sodium hypochlorite solution $(\mathrm{NaOCl})$ is the most popular root canal irrigant. Additionally, Ethylene diamine tetra-acetic Acid (EDTA) has been the irrigant of choice for removal of smear layer when Na$\mathrm{OCl}$ has been used throughout instrumentation ${ }^{[2]}$.

Conventional needle and syringe irrigation delivers solution only $1 \mathrm{~mm}$ beyond the needle tip ${ }^{[3]}$. This is insufficient for the cleaning of the complex anatomy of the root canal.

Different agitation techniques have been used for better distribution of the irrigants into the root canal. Manual dynamic activation (MDA) is a costeffective technique for cleaning the root canal. It involves insertion of a well-fitting gutta-percha cone to working length of a previously shaped canal in short strokes to hydrodynamically displace and agitate an irrigant ${ }^{[4]}$.

Passive ultrasonic irrigation (PUI) is based on the use of an ultrasound-activated file into root canal filled with irrigant to induce acoustic microstreaming and cavitations in the irrigant around the tip to enhance the removal of the smear layer ${ }^{[5]}$.

A new method of disinfection called photoactivated disinfection (PAD) has been developed It is based on two components: a non-toxic dye termed as photosensitizer (PS) and a light system of a specific wavelength $(635 \mathrm{~nm})$ for root canal disinfection ${ }^{[6]}$.

Limited information is available on evaluating smear layer removal with photoactivated disinfection, therefore this study was conducted.

\section{MATERIALS AND METHODS}

\section{Study design}

This is a prospective, randomized laboratory study.

\section{Study setting}

Single rooted human premolars were selected from recently extracted teeth for orthodontic or periodontal reasons from the outpatient clinic of Oral Surgery Department, Faculty of Dentistry, Tanta University.

\section{Sample size}

Sixty extracted single rooted human premolars.

\section{Teeth selection}

\section{Inclusion criteria}

Single rooted human premolars with nearly straight single canal with approximately similar apical diameters (size \#20).

\section{Exclusion criteria}

Teeth with any root caries, resorptive defects, previous root canal treatment, radiographically invisible root canal, cracks or fractures detected after radiographic examination were excluded from this study.

\section{Ethical considerations}

Approval for this research was obtained from Research Ethics Committee, Faculty of Dentistry, Tanta University. The purpose of the present study was explained to the patients and informed consents were obtained to use their extracted teeth in the research according to the guidelines on human research adopted by the Research Ethics Committee at Faculty of Dentistry, Tanta University.

\section{Sample collection}

Teeth were cleaned from soft tissues and calculus using a hand scaler, washed with water then stored in sterile normal saline solution at room temperature which was changed every 24 hours until the teeth were used within three months after extraction[7]. The crowns of all teeth were removed near the level of cementoenamel junction with a 
diamond disk"attached to a slow speed handpiece* under copious amount of water to obtain approximately $15 \pm 1 \mathrm{~mm}$ uniform root lengths. The root canals were negotiated with hand stainless steel Kfile $\# 10^{* *}$ to ensure apical patency. Then K-file \#15 was inserted until its tip was just visible at the apical foramen and working length was determined visually by subtracting $1 \mathrm{~mm}$ from this length. Root apex was sealed with melted wax to close the apical foramen and prevent irrigants from escaping through the apex to simulate clinical conditions ${ }^{[8]}$.

\section{Root canal instrumentation:}

Root canals were prepared using nickel-titanium rotary ProTaper Next files ${ }^{\ddagger}$ up to an apical size corresponding to X4 (\#40 / 0.06) in a crown down manner at $300 \mathrm{rpm}$ and $2 \mathrm{Ncm}$ torque using a torquecontrolled endodontic motor ${ }^{* * *}$ according to the manufacturer instructions. Each canal was irrigated with $3 \mathrm{~mL}$ of $2.5 \% \mathrm{NaOCl}$ solution between each file size using a $3 \mathrm{~mL}$ plastic disposable syringe and NaviTip ${ }^{* * * *} 30$-gauge tip inserted deeply $2 \mathrm{~mm}$ from the working length. After instrumentation, all canals were rinsed with $1 \mathrm{~mL}$ of $17 \%$ EDTA that was left in the canal for 1 minute and finally washed with $3 \mathrm{~mL}$ of $2.5 \% \mathrm{NaOCl}$ solution.

\section{Study groups}

Roots were randomly divided into 4 equal groups $(n=15)$ according to the final irrigation protocols as follows:

- Group I: Root canals were left without final activation representing conventional needle and syringe irrigation.

\footnotetext{
* Komet; Brasseler, Lemgo, Germany.

** NSK, Tokyo, Japan

*** Dentsply Maillefer, Ballaigues, Switzerland.

**** Endo E Class, Marathon, Daegu, Korea.

***** Ultradent Products Inc, South Jordan, UT.

****** Apoza, New Taipei City, Taiwan, R.O.C.

\# Diadent, Chungcheongbuk-do, korea

\#\# Aceton Group,Paris, France.

\#\#\# Discus Dental, Culver City,GA.
}

- Group II: Final rinse with $5 \mathrm{~mL}$ of $2.5 \% \mathrm{NaOCl}$ solution that was activated with a well-fitting gutta-percha cone.

- Group III: Final rinse with $5 \mathrm{~mL}$ of $5.25 \%$ $\mathrm{NaOCl}$ solution which was activated with passive ultrasonic irrigation.

- Group IV: Root canals were finally irrigated with photo activated disinfection ${ }^{* * * * *}$

In Manual dynamic agitation group (Group II): Canal was flooded with $5 \mathrm{~mL}$ of $2.5 \% \mathrm{NaOCl}$ solution and activated at the working length using \# 40, 0.06 gutta-percha cone ${ }^{\#}$ for one minute. The activation's frequency was nearly 100 push-pull strokes per minute.

In PUI group (Group III): $5 \mathrm{~mL}$ of $2.5 \% \mathrm{NaOCl}$ solution was passively activated using an ultrasonic device $^{\# \#}$ for 1 minute. \#10 endosonic file $\mathrm{e}^{\# \# \#}$ was inserted $2 \mathrm{~mm}$ short of the working length. The endosonic file was activated at medium power setting of $10^{[9]}$.

In PAD group (Group IV): LED with a wavelength of $635 \mathrm{~nm}$ was used as a source of light, disposable conical plastic tip was used for light delivery. The photosensitizer was a watery solution of toluidine blue which was prepared to $50 \mu \mathrm{g} / \mathrm{mL}$ concentration and stored in the dark at $4^{\circ} \mathrm{C}$ until its usage ${ }^{[10]}$. A volume of $75 \mu \mathrm{L}$ of toluidine blue was introduced into the root canal using 27 gauge sterile endodontic micro-needle ${ }^{[11]}$, then was agitated for 60 sec. using \#40 K-file. The tip attached to the LED device was placed $2 \mathrm{~mm}$ short of the working length ${ }^{[12]}$. Activation of the photosensitizer was continued for $60 \mathrm{sec}$. 
After completion of final irrigation activation, all roots were rinsed with $5 \mathrm{~mL}$ distilled water and dried with sterile absorbent paper points.

\section{Evaluation of canal cleanliness using scanning electron microscope (SEM)}

Wax of each root was removed from the apical foramen then a small cotton pellet was placed putted inside the coronal opening of each canal to prevent the debris from entering the root canal throughout sectioning.

Roots were splitted longitudinally in a buccolingual direction to expose their interior by cutting two grooves on the buccal and lingual aspects of each root using a slow speed diamond disc. The grooves were not deep enough to enter the canals, and then a plastic instrument was used to cleave the root into two longitudinal halves ${ }^{[13]}$. The root half with better exposure of the apex was chosen and coded for examination by SEM $^{*}$ and the other one was discarded. The root halves were dehydrated with ascending concentrations of ethyl alcohol (30$100 \%$ ), placed in a desiccator for at least 24 hours, then mounted on aluminum stubs, sputter goldcoated to render the surface electrically conductive, and then examined under SEM using different magnification (X350- X1000) $)^{[14]}$.

Canal cleanliness was evaluated at the coronal, middle, and apical root canal thirds ( $\mathrm{C}, \mathrm{M}$, and $\mathrm{A}$ ) according to a 4-category scale system which was used for debris and smear layer as follow ${ }^{[15]}$ :

- Score 1: Presences of debris/smear layer that covers $0-25 \%$ of the surface examined.

- Score 2: Presences of debris/smear layer that covers $25-50 \%$ of the surface examined.

- Score 3: Presences of debris/smear layer that covers $50-75 \%$ of the surface examined.

- Score 4: Presences of debris/smear layer that covers $75-100 \%$ of the surface examined.

\section{Statistical analysis:}

Scores percentage of root canal cleanliness for all groups at each root canal level were collected, tabulated and statistically analyzed using KruskalWallis test with a statistical significant difference at $\mathrm{P} \leq 0.05$, then multiple pairwise comparisons were performed using Mann-Whitney U test. SPSS software version 20 was used in all statistical analysis.

\section{RESULTS}

For all tested groups, the coronal thirds recorded the best result, while the apical thirds recorded the worst result for canal cleanliness. Statistical analysis was performed using Kruskal-Wallis and revealed significant difference $(P<0.05)$ among the three root canal levels in all groups (Table 1).

Mann-Whitney pairwise comparison test showed statistical significant differences between coronal and apical levels in all tested groups, also between middle and apical levels in all tested groups except in group III

When comparing canal cleanliness for different methods of final irrigation activation regardless canal levels, Group III has the best cleanliness of the root canal with statistical significant differences between the tested groups $(P=0.006)$ using Kruskal-Wallis. Pairwise comparison revealed statistical significant differences between Group I versus Group II ( $P$ $=0.027)$, Group I versus Group III $(P=0.001)$, and Group III versus Group IV $(P=0.049)$.

When comparing canal cleanliness of root canal levels regardless the method of final irrigation activation, the least amount of smear layer and remaining debris was recorded at the coronal level, while the highest amount was recorded at the apical level with a statistical significant difference between the root canal levels. Pairwise comparison showed statistical significant differences between coronal and apical levels $(P<0.001)$ and between middle and apical levels $(P<0.001)$.

\footnotetext{
* JSM-52500 scanning electron microscope, JEOL, Japan.
} 
TABLE (1) Numbers and score percentages of smear layer and remaining debris at three tested root levels of all tested groups

\begin{tabular}{|c|c|c|c|c|c|c|c|c|c|c|c|c|}
\hline \multirow[t]{2}{*}{ Groups } & \multirow{2}{*}{$\begin{array}{c}\text { Canal } \\
\text { cleanliness }\end{array}$} & \multicolumn{2}{|c|}{ Coronal } & \multicolumn{2}{|c|}{ Middle } & \multicolumn{2}{|c|}{ Apical } & \multicolumn{2}{|c|}{$\begin{array}{c}\text { Kruskal- } \\
\text { Wallis Test }\end{array}$} & \multicolumn{3}{|c|}{$\begin{array}{c}\text { Mann-Whitney } \\
\text { Test }\end{array}$} \\
\hline & & $\mathbf{N}$ & $\%$ & $\mathbf{N}$ & $\%$ & $\mathbf{N}$ & $\%$ & $\mathbf{X}^{2}$ & $P$-value & C\&M & C\&A & M\&A \\
\hline \multirow{5}{*}{ G I } & Score 1 & 6 & 40.00 & 5 & 33.33 & 1 & 6.67 & \multirow{5}{*}{20.878} & \multirow{5}{*}{$<0.001 *$} & \multirow{5}{*}{0.562} & \multirow{5}{*}{$<0.001 *$} & \multirow{5}{*}{$<0.001^{*}$} \\
\hline & Score 2 & 9 & 60.00 & 9 & 60.00 & 2 & 13.33 & & & & & \\
\hline & Score 3 & 0 & 0.00 & 1 & 6.67 & 5 & 33.33 & & & & & \\
\hline & Score 4 & 0 & 0.00 & 0 & 0.00 & 7 & 46.67 & & & & & \\
\hline & Median & \multicolumn{2}{|c|}{2} & \multicolumn{2}{|c|}{2} & \multicolumn{2}{|c|}{3} & & & & & \\
\hline \multirow{5}{*}{ G II } & Score 1 & 9 & 60.00 & 7 & 46.67 & 3 & 20.00 & \multirow{5}{*}{8.901} & \multirow{5}{*}{$0.012 *$} & \multirow{5}{*}{0.472} & \multirow{5}{*}{$0.007 *$} & \multirow{5}{*}{$0.023 *$} \\
\hline & Score 2 & 6 & 40.00 & 8 & 53.33 & 7 & 46.67 & & & & & \\
\hline & Score 3 & 0 & 0.00 & 0 & 0.00 & 4 & 26.67 & & & & & \\
\hline & Score 4 & 0 & 0.00 & 0 & 0.00 & 1 & 6.67 & & & & & \\
\hline & Median & \multicolumn{2}{|c|}{1} & \multicolumn{2}{|c|}{2} & \multicolumn{2}{|c|}{2} & & & & & \\
\hline \multirow{5}{*}{ G III } & Score 1 & 1 & 73.33 & 9 & 60.00 & 5 & 33.33 & \multirow{5}{*}{6.501} & \multirow{5}{*}{$0.039 *$} & \multirow{5}{*}{0.446} & \multirow{5}{*}{$0.018^{*}$} & \multirow{5}{*}{0.073} \\
\hline & Score 2 & 4 & 26.67 & 6 & 40.00 & 7 & 46.67 & & & & & \\
\hline & Score 3 & 0 & 0.00 & 0 & 0.00 & 3 & 20.00 & & & & & \\
\hline & Score 4 & 0 & 0.00 & 0 & 0.00 & 0 & 0.00 & & & & & \\
\hline & Median & \multicolumn{2}{|c|}{1} & & 1 & & 2 & & & & & \\
\hline & Score 1 & 8 & 53.33 & 6 & 40.00 & 3 & 20.00 & & & & & \\
\hline & Score 2 & 7 & 46.67 & 9 & 60.00 & 4 & 26.67 & & & & & \\
\hline G IV & Score 3 & 0 & 0.00 & 0 & 0.00 & 5 & 33.33 & 10.709 & $0.005^{*}$ & 0.472 & $0.004 *$ & $0.010^{*}$ \\
\hline & Score 4 & 0 & 0.00 & 0 & 0.00 & 3 & 20.00 & & & & & \\
\hline & Median & & 1 & & 2 & & 3 & & & & & \\
\hline
\end{tabular}

\section{DISCUSSION}

Successful root canal treatment depends on the eradication of microorganisms by chemomechanical instrumentation of the root canal system. All endodontic instruments create smear layer due to their action on root canal walls ${ }^{[16]}$. Some have suggested the protective role of smear layer against bacterial penetration into the underlying dentinal tubules. On contrary, smear layer could prevent irrigant solutions from entering the infected dentinal tubules. Also, the smear layer removal may enhance the adaptation of obturation materials to the root canal walls ${ }^{[17]}$.

The alternate use of $\mathrm{NaOCl}$ and EDTA has been recommended for efficient removal of the smear layer ${ }^{[18]}$. So root canal irrigation in the current study was performed using $2.5 \% \mathrm{NaOCl}$ during mechanical preparation, then $1 \mathrm{~mL}$ of $17 \%$ EDTA was left in the canal for 1 minute after instrumentation and all canals were finally washed with $3 \mathrm{~mL}$ of $2.5 \%$ $\mathrm{NaOCl}$ solution. 
When traditional needle irrigation is used, the irrigants are delivered only $1 \mathrm{~mm}$ beyond the needle tip. In addition to, vapor lock that results in trapped air in the apical third of root canals that prevent the exchange of irrigants and affect their debridement efficacy. So, different final irrigant activation techniques have been proposed to improve the efficacy of irrigant solutions ${ }^{[19]}$. Therefore, three final irrigation activation techniques (manual dynamic activation, passive ultrasonic irrigation and photoactivated disinfection) were compared with conventional syringe-needle irrigation for their effectiveness in removal of smear layer and remaining debris.

In MDA, the frequency of push-pull motion of the gutta-percha was approximately 100 movements per minute, and its amplitude was approximately 3-5 $\mathrm{mm}$ in this study for adequate activation of the irrigant within the canal and avoid overzealous activation which might lead to irrigant extrusion, distortion of the gutta-percha point, and unnecessary fatigue to the operator ${ }^{[19]}$.

In PUI activation, \#10 endosonic file was used in this study to be less likely to contact the canal walls and prevent its dampening effect and inserted $2 \mathrm{~mm}$ shorter of the WL to avoid preparation of root canal walls as the contact between an ultrasonic tip and the dentinal wall may result in diminished amplitude and the reduction of irrigant's streaming velocity. Endosonic file was used on medium power to be effective in smear layer and debris removal and for 1 minute as shorter passive irrigation to keep the file in the center of the canal and therefore prevents it from touching the walls and creating aberrant forms ${ }^{[9]}$.

PAD has been proposed as auxiliary therapy in chemomechanical preparation due to its antimicrobial activity. Although this technology has shown favorable results concerning its antimicrobial activity, little information is known about their impact on the removal of smear layer and debris. In the present study LED with a wavelength of $635 \mathrm{~nm}$ was used as a source of light. The choice of toluidine blue dye as the photosensitizing agent was due to its capacity to absorb light at wavelengths from 620-660 $\mathrm{nm}$ [20], such as that of the LED used. Also the dye was prepared to $50 \mu \mathrm{g} / \mathrm{mL}$ concentration as recommended by Schlafer et al. ${ }^{[1]}$ that used concentrations varying between 10 and $100 \mu \mathrm{g} / \mathrm{ml}$.

Freshly extracted single rooted human premolars with nearly straight single root canal with approximately similar apical diameters (size \# 20) and similar root length $(15 \pm 1 \mathrm{~mm})$ were selected in this study to ensure standardization of the experimental groups.

The apex of all samples were sealed with melted was to simulate clinical situations, where the canal behaves as a closed-end channel, as the root is enclosed within the bony socket. This results in prevention of irrigant extrusion and possible gas entrapment inside the root canal creating the vaporlock effect ${ }^{[21]}$.

Rotary ProTaper Next files were used for root canal preparation up to an apical size corresponding to X4 (\#40 / 0.06), as this preparation size facilitates insertion of the irrigation activation devices and to ensure that the irrigant was delivered at working length and had enough space for adequate flow, also it allowed the beam in PAD to reach closer to the root apex.

Evaluation of canal cleanliness in terms of smear layer and remaining debris require high magnification levels that are achievable only through imaging the root canal walls with SEM, so that two magnifications (X350 and X1000) were used in this study. At low magnification (X350) large amounts of debris could be easily seen, but details such as remnants of the smear layer and identification of dentinal tubules could be seen at high magnification (X1000). In the present study, the cleaning efficiency was examined on the basis of a numerical evaluation scheme for debris and smear layer of the coronal, the middle, and the apical parts of the canals ${ }^{[22]}$. 
The findings of the present study revealed that cleaning in the apical levels were less efficient in comparison to the coronal areas in all tested groups with significant differences. Regarding the conventional syringe-needle group, this finding could be explained by the presence of apical vapor lock that results in gas entrapment at the apical third thus preventing the flow of irrigant and adequate debridement at the apical region. This finding was in agreement with the results of Rodig et al. ${ }^{[23]}$

In MDA, the significantly better removal of smear layer and debris in the coronal and middle levels than the apical level may be due to the smear layer and remaining debris do not have an apical exit that enable them to be removed, as the apical air bubble is displaced [24]. This observation was in agreement with the study of Ahuja et al. ${ }^{[25]}$

In PUI, the coronal level was significantly better cleaned than the apical level, this could be explained by the cavitation process which is only possible in fluids or liquids, not in gases. So, it is physically impossible for acoustic microstreaming and/or cavitation to disrupt the apical vapor lock. Therefore PUI cannot effectively get through the apical vapor lock ${ }^{[26]}$. This was in agreement with previous studies of Mozo et al. ${ }^{[27]}$, Cameron et al. ${ }^{[28]}$. In contrary, this result was in disagreement with Majina et al. ${ }^{[29]}$ who reported that absence of smear layer in the apical third of the root canal in PUI, while it was more evident at the coronal level. This difference could be explained by difference in methodology as the low power setting of ultrasonic device used with longer activation time and the endosonic file was inserted to the full working length.

In $\mathrm{PAD}$, the coronal and middle levels had significantly less smear layer and remaining debris than the apical level, this could be attributed to the presence of vapor lock may have hindered the action of the photosensitizing agent ${ }^{[21]}$. This finding was supported by other studies of Menezes et al. ${ }^{[30]}$ and Alonaizan et al. ${ }^{[31]}$.
When comparing between the methods of final irrigation activation regardless the root canal levels, PUI recorded more efficient canal cleanliness, this may be attributed to the transmission of acoustic energy from the oscillating file to $\mathrm{NaOCl}$ irrigant in the canal space. The energy is transmitted by means of ultrasonic waves which can induce acoustic streaming of the irrigant, resulting in better penetration and increased irrigant volume ${ }^{[19]}$. This finding was in agreement with Lee et al. ${ }^{[32]}$, while in disagreement with Saber et al. ${ }^{[33]}$, who revealed that PUI had the highest smear scores, the conflicts in results might be related to the different methodology as the different tip size and the low power setting used which might be weak to allow a proper acoustic streaming

MDA showed significantly better canal cleanliness when compared to the conventional syringeneedle irrigation, this may be attributed to the previously mentioned reasons. Better results of MDA in canal cleanliness were confirmed by Saber and Hashem ${ }^{[33]}$ and Huang et $\mathrm{al}^{[34]}$.In contrary, this result was in disagreement with Ribeiro et al. ${ }^{[35]}$, who found that MDA result in less removal of smear layer and debris. This difference may be related to the smaller sized gutta percha cone used and different mechanical preparation at working length.

PUI showed significantly better removal of the smear layer when compared to the PAD, this may be explained by using non laser light source (LED) for activation of toluidine blue dye in PAD and absence of laser irradiation with its potential effect for removal of smear layer so PAD in this study has no effect on removal of smear layer and remaining debris. This was supported by the finding of Bouillaguet et al. ${ }^{[36]}$ who suggested that common red and blue dentallight sources are useful for activating photosensitive disinfecting dyes, while laser irradiation has the potential to kill microorganisms and also to remove debris and smear layer from root canals ${ }^{[37]}$.

In the present study, PAD recorded high smear scores without significant difference with 
conventional syringe-needle irrigation, this was in disagreement with Lacerda et al. ${ }^{[38]}$, who reported that PAD resulted in reduction of the smear layer and opening of the dentinal tubules. This could be explained by different light parameters and wavelengths (arsenide, gallium, and aluminum laser diode), light delivery technique (insertion of the tip was to the WL) and interaction time of the dye with the medium.

Comparing between the three root levels regardless of the method of final irrigation activation revealed better cleaning of the coronal third followed by the middle third and finally the apical third. The decreased cleaning efficiency in the apical third of the canals was attributed to the reduced canal diameter which in turn has an impact on the effectiveness of debris removal and on the volume and exchange of irrigant at the working length. In addition, the quantity and diameter of dentinal tubules are reduced close to the apex ${ }^{[39]}$. Furthermore, dentin in the apical third of root canal is sclerosed and EDTA may not have a pronounced action on the sclerosed dentin ${ }^{[40]}$. On the other hand, a larger canal diameter in both coronal and middle thirds with higher quantity of dentinal tubules compared to apical third exposes dentin to a higher volume of irrigant allowing better flow and further improving its efficiency of smear layer removal $[41,42]$. The present results were in agreement with previous studies ${ }^{[22,43,44]}$ which confirmed that root canal cleanliness decreased from the coronal to the apical part of the root canal.

\section{CONCLUSION}

From the present study, it can be concluded that:

- None of the investigated final irrigation activation methods resulted in completely clean canal wall.

- Canal cleanliness increased from the apical to the coronal parts of the root in the tested methods of final irrigation activation

\section{REFERENCES}

1. Torabinejad M, Handysides R, Khademi AA, Bakland LK. Clinical implications of the smear layer in endodontics: a review. Oral Surg Oral Med Oral Pathol Oral Radiol Endod. 2002;94:658-66.

2. Haapasalo M, Qian W, Shen Y. Irrigation: beyond the smear layer. Endod Topics. 2012;27:35-53.

3. Munoz HR, Camacho-Cuadra K. In vivo efficacy of three different endodontic irrigation systems for irrigant delivery to working length of mesial canals of mandibular molars. J Endod. 2012;38:445-8.

4. Khaord P, Amin A, Shah MB, Uthappa R, Raj N, Kachalia $\mathrm{T}$, et al. Effectiveness of different irrigation techniques on smear layer removal in apical thirds of mesial root canals of permanent mandibular first molar: A scanning electron microscopic study. J Conserv Dent. 2015;18:321-6.

5. Guerreiro-Tanomaru JM, Chávez-Andrade GM, FariaJúnior NBd, Watanabe E, Tanomaru-Filho M. Effect of Passive Ultrasonic Irrigation on Enterococcus faecalis from Root Canals: An Ex Vivo Study. Braz Dent J. 2015;26:342-6.

6. Yao N, Zhang C, Chu C. Effectiveness of photoactivated disinfection (PAD) to kill enterococcus faecalis in planktonic solution and in an infected tooth model. Photomed Laser Surg. 2012;30:699-704.

7. Dua D, Dua A, Uppin VM. A Scanning electron microscopic evaluation of intracanal smear layer removal by two different final irrigation activation systems. Contemp Clin Dent. 2014;5:37-41.

8. Caron G, Nham K, Bronnec F, Machtou P. Effectiveness of different final irrigant activation protocols on smear layer removal in curved canals. J Endod. 2010;36:1361-6.

9. Bago Juric I, Plecko V, Anic I. Antimicrobial efficacy of Er,Cr:YSGG laser-activated irrigation compared with passive ultrasonic irrigation and $\operatorname{RinsEndo(R)}$ against intracanal Enterococcus faecalis. Photomed Laser Surg. 2014;32:600-5.

10. Shaheen NA, Ghoneim WM. Effect of different root canal disinfection protocols on push-out bond strength of two endodontic sealers. Tanta Dent J. 2017;14:181.

11. Schlafer S, Vaeth M, Horsted-Bindslev P, Frandsen EV. Endodontic photoactivated disinfection using a conventional light source: an in vitro and ex vivo study. Oral Surg Oral Med Oral Pathol Oral Radiol Endod. 2010;109:634-41. 
12. Ok E, Ertas H, Saygili G, Gok T. Effect of photo-activated disinfection on bond strength of three different root canal sealers. Eur J Dent. 2014;8:85-9.

13. Ghoneim W, Farag A, Labib A, Darrag A. Cleaning efficacy of different root canal preparation systems and irrigation regimens. Tanta Dent J. 2014;11:36-41 .

14. Khademi AA, M F. The Effect of EDTA and Citric Acid on Smear Layer Removal of Mesial Canals of First Mandibular Molars, A Scanning Electron Microscopic Study. J Res Med Sci. 2004;9:80-8.

15. Arvaniti IS, Khabbaz MG. Influence of Root Canal Taper on Its Cleanliness: A Scanning Electron Microscopic Study. J Endod. 2011;37:871-4.

16. Schafer E, Erler M, Dammaschke T. Comparative study on the shaping ability and cleaning efficiency of rotary Mtwo instruments. Part 2. Cleaning effectiveness and shaping ability in severely curved root canals of extracted teeth. Int Endod J. 2006;39:203-12.

17. Khadivi Nia Javan N, Mohajeri Baradaran L, Azimi S. SEM Study of Root Canal Walls Cleanliness after Ni-Ti Rotary and Hand Instrumentation. Iran Endod J. 2007;2:5-10.

18. Mancini M, Cerroni L, Iorio L, Armellin E, Conte G, Cianconi L. Smear layer removal and canal cleanliness using different irrigation systems (EndoActivator, EndoVac, and passive ultrasonic irrigation): field emission scanning electron microscopic evaluation in an in vitro study. J Endod. 2013;39:1456-60.

19. Andrabi SM, Kumar A, Zia A, Iftekhar H, Alam S, Siddiqui S. Effect of passive ultrasonic irrigation and manual dynamic irrigation on smear layer removal from root canals in a closed apex in vitro model. J Investig Clin Dent. 2014;5:188-93.

20. Plotino G, Grande NM, Mercade M. Photodynamic therapy in endodontics. Int Endod J. 2019;52:760-74.

21. Tay FR, Gu LS, Schoeffel GJ, Wimmer C, Susin L, Zhang $\mathrm{K}$, et al. Effect of vapor lock on root canal debridement by using a side-vented needle for positive-pressure irrigant delivery. J Endod. 2010;36:745-50.

22. Al-Ali M, Sathorn C, Parashos P. Root canal debridement efficacy of different final irrigation protocols. Int Endod J. 2012;45:898-906.

23. Rodig T, Dollmann S, Konietschke F, Drebenstedt S, Hulsmann M. Effectiveness of different irrigant agitation techniques on debris and smear layer removal in curved root canals: a scanning electron microscopy study. J Endod. 2010;36:1983-7.

24. Parente JM, Loushine RJ, Susin L, Gu L, Looney SW, Weller RN, et al. Root canal debridement using manual dynamic agitation or the EndoVac for final irrigation in a closed system and an open system. Int Endod J. 2010;43:1001-12.

25. Ahuja P, Nandini S, Ballal S, Velmurugan N. Effectiveness of four different final irrigation activation techniques on smear layer removal in curved root canals : a scanning electron microscopy study. J Dent (Tehran). 2014;11:1-9.

26. Pasricha SK, Makkar S, Gupta P. Pressure alteration techniques in endodontics- a review of literature. J Clin Diagn Res. 2015;9:Ze01-6.

27. Mozo S, Llena C, Chieffi N, Forner L, Ferrari M. Effectiveness of passive ultrasonic irrigation in improving elimination of smear layer and opening dentinal tubules. J Clin Exp Dent. 2014;6:e47-52.

28. Cameron JA. Factors affecting the clinical efficiency of ultrasonic endodontics: a scanning electron microscopy study. Int Endod J. 1995;28:47-53.

29. Majina A, Pitt Ford TR, Crum LA. Ultrasonic debridement of root canals: Acoustic streaming and its possible role. J Endod. 1987;13:490-9.

30. Menezes M, Prado M, Gomes B, Gusman H, Simao R. Effect of photodynamic therapy and non-thermal plasma on root canal filling: analysis of adhesion and sealer penetration. J Appl Oral Sci. 2017;25:396-403.

31. Alonaizan FA, Alofi RS, AlFawaz YF, Alsahhaf A, AlAali KA, Vohra F, et al. Effect of Photodynamic Therapy, Er,Cr:YSGG, and Nd:YAG Laser on the Push-Out Bond Strength of Fiber Post to Root Dentin. Photobiomodul Photomed Laser Surg. 2020;38:24-9.

32. Lee SJ, Wu MK, Wesselink PR. The effectiveness of syringe irrigation and ultrasonics to remove debris from simulated irregularities within prepared root canal walls. Int Endod J. 2004;37:672-8.

33. Saber SE-D, Hashem AAR. Efficacy of different final irrigation activation techniques on smear layer removal. J Endod. 2011;37:1272-5.

34. Huang TY, Gulabivala K, Ng YL. A bio-molecular film exvivo model to evaluate the influence of canal dimensions and irrigation variables on the efficacy of irrigation. Int Endod J. 2008;41:60-71. 
35. Ribeiro EM, Silva-Sousa YT, Souza-Gabriel AE, SousaNeto MD, Lorencetti KT, Silva SR. Debris and smear removal in flattened root canals after use of different irrigant agitation protocols. Microsc Res Tech. 2012;75:781-90.

36. Bouillaguet S, Wataha JC, Zapata O, Campo M, Lange N, Schrenzel J. Production of reactive oxygen species from photosensitizers activated with visible light sources available in dental offices. Photomed Laser Surg. 2010;28:519-25.

37. Jurič IB, Anić I. The Use of Lasers in Disinfection and Cleanliness of Root Canals: a Review. Acta Stomatol Croat. 2014;48:6-15.

38. Lacerda MFLS, Lima COd, Lacerda GP, Campos CN Evaluation of the dentin changes in teeth subjected to endodontic treatment and photodynamic therapy. Rev Odontol UNESP. 2016;45:339-43.

39. de Gregorio C, Arias A, Navarrete N, Del Rio V, Oltra E, Cohenca N. Effect of apical size and taper on volume of irrigant delivered at working length with apical negative pressure at different root curvatures. J Endod. 2013;39:119-24.
40. Paque F, Luder HU, Sener B, Zehnder M. Tubular sclerosis rather than the smear layer impedes dye penetration into the dentine of endodontically instrumented root canals. Int Endod J. 2006;39:18-25.

41. Yamashita JC, Tanomaru Filho M, Leonardo MR, Rossi MA, Silva LA. Scanning electron microscopic study of the cleaning ability of chlorhexidine as a root-canal irrigant. Int Endod J. 2003;36:391-4.

42. Torabinejad M, Khademi AA, Babagoli J, Cho Y, Johnson WB, Bozhilov K, et al. A new solution for the removal of the smear layer. J Endod. 2003;29:170-5.

43. Burklein S, Hinschitza K, Dammaschke T, Schafer E. Shaping ability and cleaning effectiveness of two singlefile systems in severely curved root canals of extracted teeth: Reciproc and WaveOne versus Mtwo and ProTaper. Int Endod J. 2012;45:449-61.

44. Urban K, Donnermeyer D, Schafer E, Burklein S. Canal cleanliness using different irrigation activation systems: a SEM evaluation. Clin Oral Investig. 2017;21:2681-7. 